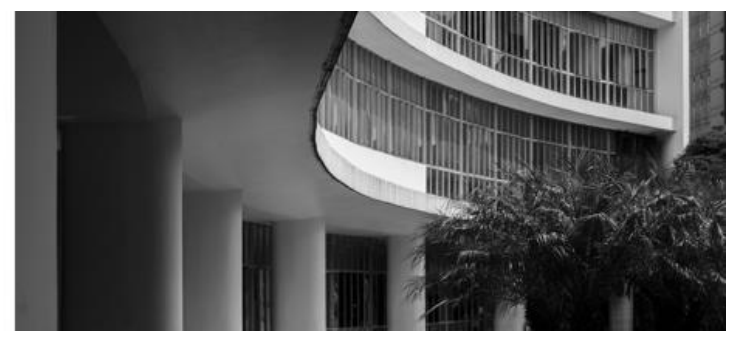

\title{
A ANTIGA CENTRAL DE POLÍCIA E UM PROPÓSITO INESPERADO: Preservação do patrimônio tombado por meio de novo uso pelo estado.
}

\section{COSTA, MARÍLIA JERONIMO (1); COUTINHO, IURY BARBOSA GRÉCIA (2); GRÉCIA, GIULIANA FORMIGA (3); TIMÓTHEO, JUSSARA BIÓCA DE MEDEIROS}

(4).

1. Faculdade Internacional da Paraíba - FPB. Curso de Arquitetura e Urbanismo.

Av. Monsenhor Walfredo Leal, 512. Tambiá. João Pessoa/PB. 58020-540

marilia.costa@fpb.edu.br

2. FUNEPI - Faculdade da União de Ensino e Pesquisa Integrada. Curso de Engenharia de Segurança do Trabalho.

Rua Hidelbrando Tourinho, 177. Jardim Rosas. João Pessoa/PB. 58032-020

iurygrecia@gmail.com

3. Faculdade Internacional da Paraíba - FPB. Curso de Arquitetura e Urbanismo.

Av. Monsenhor Walfredo Leal, 512. Tambiá. João Pessoa/PB. 58020-540

giulianagrecia.arq@gmail.com

4. Faculdade Internacional da Paraíba - FPB. Curso de Arquitetura e Urbanismo.

Av. Monsenhor Walfredo Leal, 512. Tambiá. João Pessoa/PB. 58020-540

jbioca@gmail.com

\section{RESUMO}

O presente trabalho tem como objeto de estudo o prédio da Cadeia Nova, situado no bairro do Varadouro, que se encontra dentro da poligonal de proteção do Instituto do Patrimônio Histórico e Artístico de Estado da Paraíba - IPHAEP. O prédio em tela consta nos registros cartográficos da cidade de João Pessoa desde 1858, sendo assim, pode ser considerado parte importante da história e identidade da cidade. Desse modo, como um documento histórico, deve ser preservado. Por tanto, a falta de utilização acelera o processo de perecimento do edifício; na teoria de Amorim, 2017, consiste em uma "morte anunciada", pois segundo o autor um edifício tombado pode sofrer com diversas formas de óbito. Há de se demonstrar por meio deste estudo que a edificação passou por muitas questões desde o seu "nascimento", padecendo de patologias até a pretensão de "ressurgimento" com uma nova destinação, mas preservando toda história, toda "experiência de vida" obtida ao longo dos anos quando abrigou uma unidade de reclusão prisional, a sede de uma Secretaria de Viação e Obras Públicas em 1962 até ser definitivamente desocupado pela Polícia do Estado. Tais fatos só comprovam a necessidade de utilização do patrimônio arquitetônico protegido por meio de técnicas construtivas cujas alterações no bem não constituam agressões permanentes. 
Com o intuito de divulgar o projeto de intervenção no edifício, que viabiliza seu uso como forma de evitar o seu perecimento, bem como propor a utilização dos prédios históricos por órgãos públicos com a finalidade de salvaguardar esse patrimônio do descaso de seus proprietários - os quais muitas vezes deixam que o bem pereça para negociar o lote vazio - essa pesquisa se estrutura. Diante dos dados apontados urge à população o conhecimento da necessidade de utilização como forma de preservação, para que compreendam que a partir do uso nosso patrimônio histórico estará ainda mais salvaguardado. É inegável que a manutenção diária oriunda da utilização passa a ser preventiva e periódica, mantendo viva uma região silenciada pelo abandono. Todavia é questionável até que ponto o referido projeto de intervenção expõe o bem, muito embora permita que sua readequação de finalidade seja um passo promissor em direção ao reavivamento do sitio onde está inserido.

Palavras-chave: Cadeia Nova; CHJP - Centro Histórico de João Pessoa; Conservação; Documentação; Patrimônio.Fonte Arial 10, separadas por ponto e virgula, três a cinco palavras. 


\section{INTRODUÇÃO}

O presente trabalho tem como objeto de estudo o prédio da Cadeia Nova, situado no bairro do Varadouro, na cidade de João Pessoa - PB. Encontra-se dentro da poligonal de proteção do Instituto do Patrimônio Histórico e Artístico de Estado da Paraíba - IPHAEP e, consta nos registros cartográficos da capital paraibana desde 1858, sendo assim, pode ser considerado parte importante da história e identidade da cidade. (Figura 1)

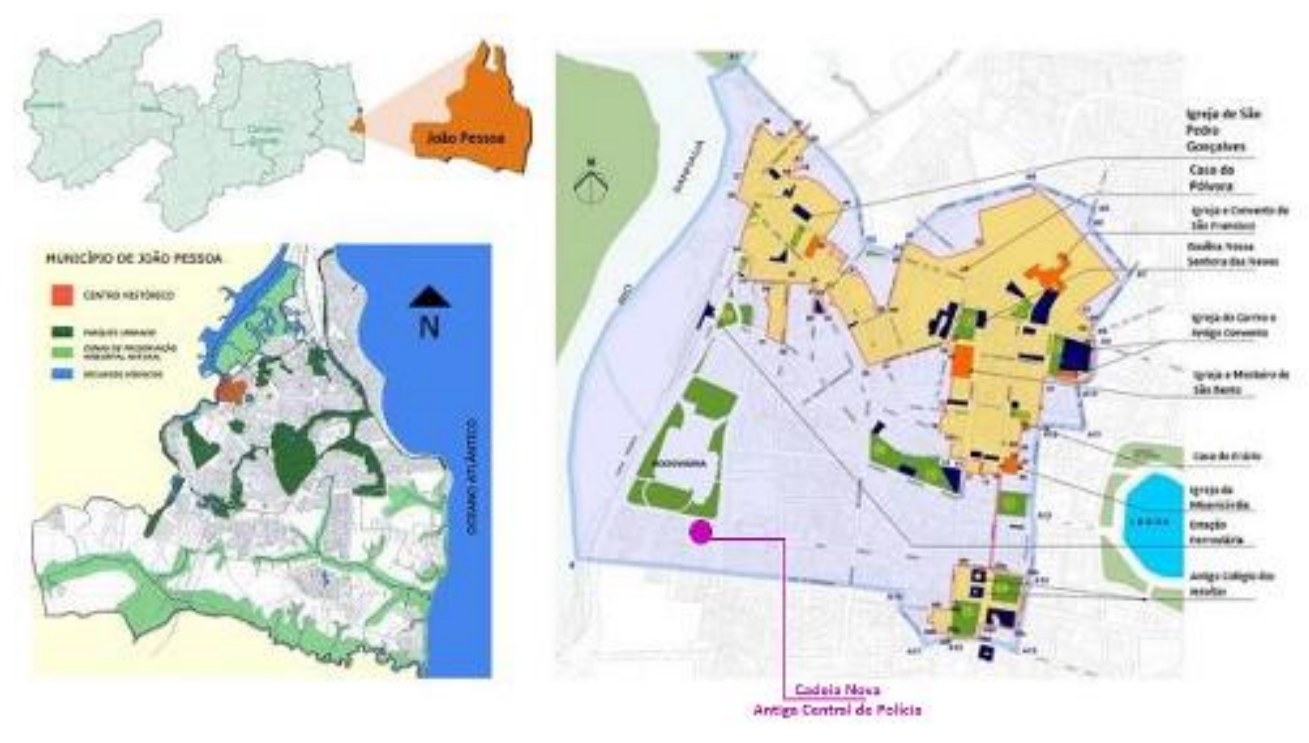

Figura 1- Mapa de Localização da cidade de João Pessoa e em destaque o Centro Histórico de João Pessoa - perímetro da poligonal de tombamento - em destaque o prédio da Cadeia Nova.

Fonte: COSTA, 2015, p. 23. Editado pelos autores.

Desse modo, como um documento histórico, deve ser preservado. Por tanto, a falta de utilização acelera o processo de perecimento do edifício; na teoria de Amorim (2017), consiste em uma "morte anunciada", pois segundo o autor um edifício tombado pode sofrer com diversas formas de óbito, sendo essa, a que melhor se adéqua ao caso. Há de se demonstrar por meio deste estudo que a edificação passou por muitas questões desde o seu "nascimento", padecendo de patologias até a pretensão de "ressurgimento" com uma nova destinação, mas preservando toda história, toda "experiência de vida" obtida ao longo dos anos quando abrigou uma unidade de reclusão prisional, a sede da Secretaria de Viação e Obras Públicas em 1962, precursora da Superintendência de Obras do Estado SUPLAN até ser definitivamente desocupada pela Polícia do Estado, em decorrência da inadequação física das instalações, finalizando assim as atividades como uma Central de Polícia. Tais fatos só comprovam a necessidade de utilização do patrimônio arquitetônico protegido por meio de técnicas construtivas cujas alterações no bem não constituam agressões permanentes, mas sim possibilitando sua ocupação com função diversa. 


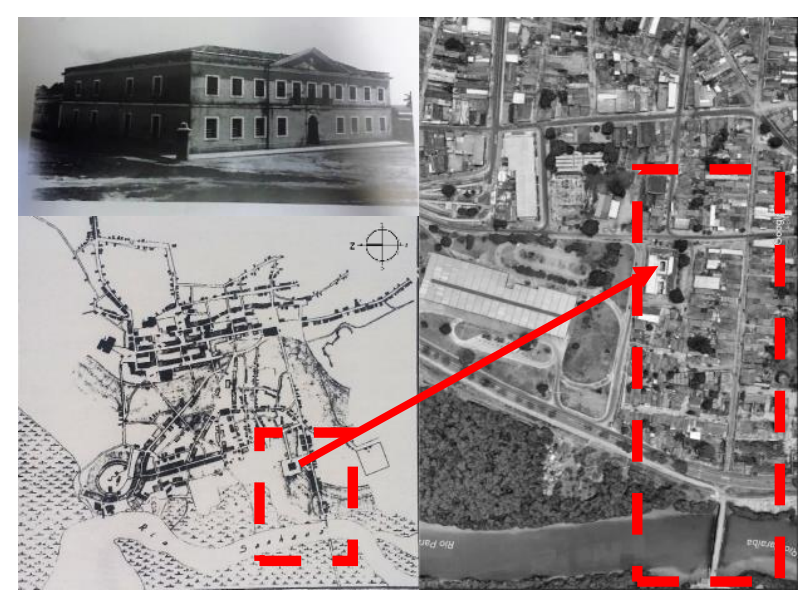

Fonte: Diversas

Com o intuito de divulgar o projeto de intervenção no edifício, que viabiliza seu uso como forma a evitar o seu perecimento, bem como propor a utilização dos prédios históricos por órgãos públicos com a finalidade de salvaguardar esse patrimônio do descaso de seus proprietários, - os quais muitas vezes deixam que o bem pereça para negociar o lote vazio, justificativa essa que possibilita a desapropriação do edifício pelo Estado, devido ao risco de dano ou descaracterização do bem, permitindo que este seja incorporado ao patrimônio estatal - essa pesquisa se estrutura.

Diante dos dados apontados urge à população o conhecimento da necessidade de utilização como forma de preservação, para que compreendam que a partir do uso nosso patrimônio histórico estará ainda mais salvaguardado. É inegável que a manutenção diária oriunda da utilização passa a ser preventiva e periódica, mantendo viva uma região silenciada pelo abandono. Todavia é questionável até que ponto o referido projeto de intervenção expõe a construção, muito embora permita que sua readequação de finalidade seja um passo promissor em direção ao reavivamento do sítio onde está inserido. Medidas assim já foram tomadas pelo estado do Amazonas, mais precisamente na cidade Manaus, conhecida como a "Paris dos Trópicos", ela guarda exemplares históricos, cuja preservação tornou-se prioridade das políticas públicas. As deliberações adotadas consistem desde as mais simples, como incentivos fiscais com a finalidade de promover a manutenção adequada, disponibilização do corpo técnico dos institutos de proteção ao patrimônio histórico e cultural para consulta popular e assistência aos proprietários de edifícios ou sítios protegidos, às mais complexas que foram recentemente incluídas na Lei Orgânica do Município de Manaus - LOMAN, aprovada no ano de 2005, a qual tem como parâmetro principal punições bem definidas para aqueles que colocarem o patrimônio cultural em risco.

Assim o trabalho aqui formulado, tem como finalidade última, demonstrar a necessidade de previsões legais e padrões administrativo-executivos, que permitam que o Estado cumpra seu papel de guardião e administrador dos bens culturais. Uma ação conjunta, cujas diretrizes comportam a participação popular e estatal, na busca de uma 
finalidade comum, a proteção, utilização e promoção de tudo o que compõe a identidade da cidade, possui mais chance de êxito que a mera tentativa de manutenção de algo que as gerações mais novas da cidade desconhecem, pois é difícil proteger bens cujo valor histórico não foi vivido pelos indivíduos mais jovens de uma sociedade. Tal medida torna-se ainda mais evidente na era da informatização, da virtualização das relações e da constante necessidade do novo. A implementação de políticas baseadas na educação, proteção e coerção formam uma tríade muito usada pelo Estado, mesmo antigo, esse tripé vem promovendo a criação de legislações efetivas e com um grau satisfatório de resposta.

No caso abordado nesse artigo, o prédio sempre foi utilizado pelo poder público, não possuindo os entraves provocados pela propriedade privada, cuja legislação possui uma amplitude maior, tal fato torna ainda mais evidente a necessidade de manter o patrimônio cultural sob a propriedade e tutela estatal, pois mesmo tendo passado por um período de desocupação, é fato notório que o edifício em questão possuiu mais rotatividade de uso que um prédio privado. Há desse modo, uma ótica multidisciplinar do problema, a qual não pode ser solucionada unicamente pela legislação ou pelos arquitetos, visto que sob um prisma maior projetos de proteção ao patrimônio cultural, revitalização, restauração ou readequação, que obtiveram êxito, iniciaram-se pelo clamor popular, atendido pelo Estado e abraçado pela população.

Na pesquisa abordada, a Cadeia Nova, a priori, passaria por uma adequação de uso, que observando de uma forma progressiva, produziria em seu entorno o efeito da chamada "acupuntura urbana", Lerner (2003), ou seja, a inserção de cidadãos no ambiente renovaria a "fluidez" da região, da mesma forma que em Lisboa, onde a presença de estudantes fomenta o funcionamento de equipamentos públicos e privados, os quais em sua maioria funcionam em horários variados e até mesmo contínuos, evitando assim, que a região possua horários de muito movimento e baixo movimento como ocorre atualmente, pois durante o período das 18 às 08 horas, o centro se desertifica, tornando-se área propícia para criminalidade.

Nesse sentido a SUPLAN, iniciou um projeto ambicioso: transformar a Cadeia Nova, em uma Escola Técnica de Artes e Dança. Tal empreitada teve como condicionantes principais a classificação prevista para o imóvel como de conservação parcial e o antigo uso, este mais complexo do que aquele, pois seria preciso transformar celas em alojamentos, salas de aulas, salas de música, banheiros e vestiários, tudo atendendo às normas de acessibilidade e conforto, sem descaracterizar a edificação. Assim sendo, apesar de inicialmente ser um projeto desafiador no que se diz respeito aos aspectos arquitetônicos e 
de restauração, é também uma intervenção de extrema importância para a manutenção do prédio enquanto lugar, já que o seu novo uso garantirá uma identificação dos indivíduos mais jovens com a construção e, sendo identidade para os cidadãos será, mais uma vez, identidade para a cidade.

A pesquisa contempla 3 (três) partes: A primeira estabelece a relação entre 0 patrimônio e as legislações; a segunda parte apresenta a edificação, sua história e o espaço onde está inserida - O CHJP e a última analisa o projeto de intervenção proposto para o imóvel que viabilizará a implantação da Escola Técnica de Artes e Dança.

\section{O PATRIMÔNIO EDIFICADO E O DIREITO}

O patrimônio edificado constitui a identidade de um lugar, molda suas "feições", transmitindo suas experiências e acontecimentos, pois tudo que é construído possui a marca de determinada época e assume um fragmento da história.

É por meio dos mais diversos edifícios, monumentos, praças e largos, etc. que a cidade e sua respectiva população expressa seu "modus vivendl". É através da arquitetura que entendemos a história de vida de determinado lugar. Assim é evidente a necessidade de preservação desse patrimônio, pois o perecimento deste implica à perda da própria história de uma sociedade.

Segundo Nilson Ghirardello e Beatriz Spisso (2008) a identidade cultural de uma população se faz, também, através da preservação do Patrimônio Histórico. Este patrimônio deve ser visto como um grande acervo, que é o registro de acontecimentos e fases da história de uma cidade e é representado pelo estoque construído considerando como [...] "edificações isoladas ou conjunto de edificações, que poderão ter tipologias distintas e não necessariamente antigas, mas que possuam peculiaridades culturais", no mesmo interim Souza (1982), reforça o conceito de patrimônio edificado ao estabelece-lo como um bem cultural que é produzido por um determinado povo, nação ou civilização.

Isabelle Cury (2014) assinala que a Carta de Atenas (1933) já citava que os valores arquitetônicos devem ser salvaguardados, sejam edifícios isolados ou conjuntos urbanos. A

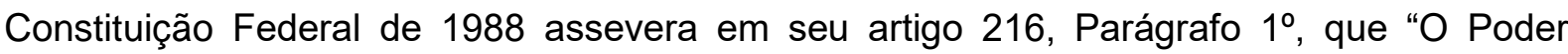
Público, com a colaboração da comunidade, promoverá e protegerá o patrimônio cultural brasileiro, por meio de inventários, registros, vigilância, tombamento e desapropriação, e de outras formas de acautelamento e preservação", isto é, no texto constitucional o reconhecimento do patrimônio edificado já se constitui uma atitude preservacionista, sendo 
reconhecido como uma das formas de proteção do patrimônio cultural de um país, estado ou município. Por meio do cadastramento é possível garantir o direito que cada comunidade tem de conhecer o seu passado e a formação de sua identidade cultural.

Sempre que um determinado bem necessita de proteção, o Direito vem com um arcabouço, cujo objetivo permite a tutela do uso e propriedade de determinado bem. Com o patrimônio não foi diferente, pois o fato de este ligar-se a história da humanidade, o torna ainda mais passível da guarda proporcionada pelo ordenamento jurídico. É no ramo do Direito Difuso que essa proteção encontra respaldo. Vale lembrar que esse em particular, protege bens que tem como sujeitos a humanidade como um todo, não havendo assim um titular em específico. Esse tipo de tutela demonstra o quão significativo é aquele bem, e o como sua perda pode ser desastrosa. Tal provisão encontra-se prevista na Carta Magna, no seu art. 225, por meio do qual temo inclusive a definição de meio ambiente Cultural, este segundo Luíz Paulo Sirvinkas consiste em:

"É uma espécie de meio ambiente ecologicamente equilibrado previsto no art. 225 da CF. Considera-se meio ambiente cultural o patrimônio cultural nacional, incluindo as relações culturais, turísticas, arqueológicas, paisagísticas e naturais. Esse patrimônio está expressamente previsto nos artigos 215 e 216 da CF." (SIRVINKAS, 2005, p. 279).

Desse modo, podemos compreender, que o patrimônio cultural, configura um direito fundamental inerente ao ser humano, sendo desse modo elevado ao Direito Fundamental que o indivíduo tem de existir, de habitar e de compor seu espaço e sua história, o direito do homem à cidade.

\section{A CADEIA NOVA QUE FICOU VELHA}

Edificação com dois pavimentos implantada na lateral da praça Firmino da Silveira, atual entroncamento das ruas Visconde de Itaparica e Francisco Londres no bairro do Varadouro. Destacava-se no cenário da área por sua proporção e imponência. Concluída em 1858, conforme registros gráficos identificados nas pesquisas desenvolvidas sobre a historiografia urbanística da cidade por Souza e Vidal (2010, p.15 e p.46). A cadeia nova foi edificada, com a finalidade precípua de abrigar apenados, uma vez que a "antiga" localizada no largo do Erário, atual Praça Rio Branco, bairro do Centro, passou a abrigar as funções do Paço Municipal em 1889.

A configuração original apresentava em sua volumetria externa características neoclássicas, com um corpo acentuadamente horizontal, com térreo e mais um pavimento e um frontão triangular destacando a simetria prolongada na platibanda pela sequencia de 
frisos que percorrem todo o perímetro. As fenestrações correspondentes as janelas possuíam formato retangular com verga reta e eram marcadas por cercaduras que reforçavam a rigidez geométrica pois encontravam-se distribuídas de forma idêntica nos dois pisos e eram guarnecidas de gradis. A porta de acesso no centro da fachada principal era destacada pela forma e dimensão, apesar de contornada com a mesma cercadura das janelas diferenciava-se pelo arco pleno. A edificação possuía planta quadrada com pátio central descoberto. Essa forma é justificada pela função e a necessidade de segurança é marcada pelo rigor da execução, com alvenarias de 1,40m de largura no piso inferior e 0,68m no piso superior além da mesma divisão espacial dos ambientes, gerando assim planta simétrica e idêntica em ambos os pisos. A coberta em duas águas, tesouras em madeira e telha cerâmica capa canal completavam a composição.

Contudo, o passar dos anos, provocou inúmeras alterações no edifício, em virtude da necessidade de aumento da capacidade prisional, iniciando assim, um processo de inadequação funcional, que culminou em ampliação da área construída a nível de planta, marcado pelo acréscimo de uma nova ala com outro pátio central e adição de um terceiro pavimento ao longo de toda extensão do edifício, parte antiga e a parte nova.

A sua utilização ficou difícil mesmo após a ampliação, não conseguindo abrigar uma unidade prisional, cujos regramentos feitos pelo Ministério da Defesa, bem como a Secretaria de Estado de Segurança e os atuais entendimentos dos Direitos Humanos exigem uma forma diversa daquela adotada em 1920, desse modo, a partir desta data vários usos foram destinados ao edifício, identificados em placas afixadas nas paredes do próprio imóvel. (Tabela 1)

\begin{tabular}{|c|c|}
\hline \multicolumn{2}{|c|}{ Registro de Usos que o Edifício Abrigou } \\
\hline Data & Uso \\
\hline 1962 & $\begin{array}{c}\text { Término da execução das obras no edifício e implantação da Secretaria de Viação } \\
\text { e Obras Públicas do Estado da Paraíba }\end{array}$ \\
\hline 1994 & Implementação da Central de Polícia \\
\hline 2010 & Inauguração do auditório Delegado Diógenes Firmino do Nascimento \\
\hline
\end{tabular}

Tabela 1: usos

Fontes: Placas metálicas das inaugura afixadas no prédio

É de inegável necessidade a preservação da edificação que retrata a identidade dos edifícios institucionais do início do século XX, assim como a dificuldade de fazê-lo sem uma 
utilização, desse modo nos valemos do conceito de salvaguarda para justificar a propositura de reocupação bem como de modificação do uso. Considerando a necessidade de uma novo uso o qual nesse sentido não anuncia a manutenção do antigo por meio de nova intervenção. Assim em virtude de sua forma construtiva, a utilização do prédio para uma finalidade diversa tornou-se um desafio, um condicionante, que associada à proteção do patrimônio tornou a reutilização do espaço ainda mais complexa.

\section{ANALISE DO PROJETO PROPOSTO}

Duas condicionantes fundamentais foram traçadas para a idealização do projeto da Escola Técnica de Artes de João Pessoa: a primeira residia na implantação adequada de um projeto que respeitasse a historicidade da edificação, para tanto foram realizados estudos e acompanhamentos em parceria com o IPHAEP - Instituto do Patrimônio Histórico e Artístico do Estado da Paraíba, a segunda condicionante consistia na aplicação do programa de necessidades exigido pela Secretaria de Estado da Educação e da Cultura. Este dividido em dois grupos: pedagógico e administrativo (Figura 2).

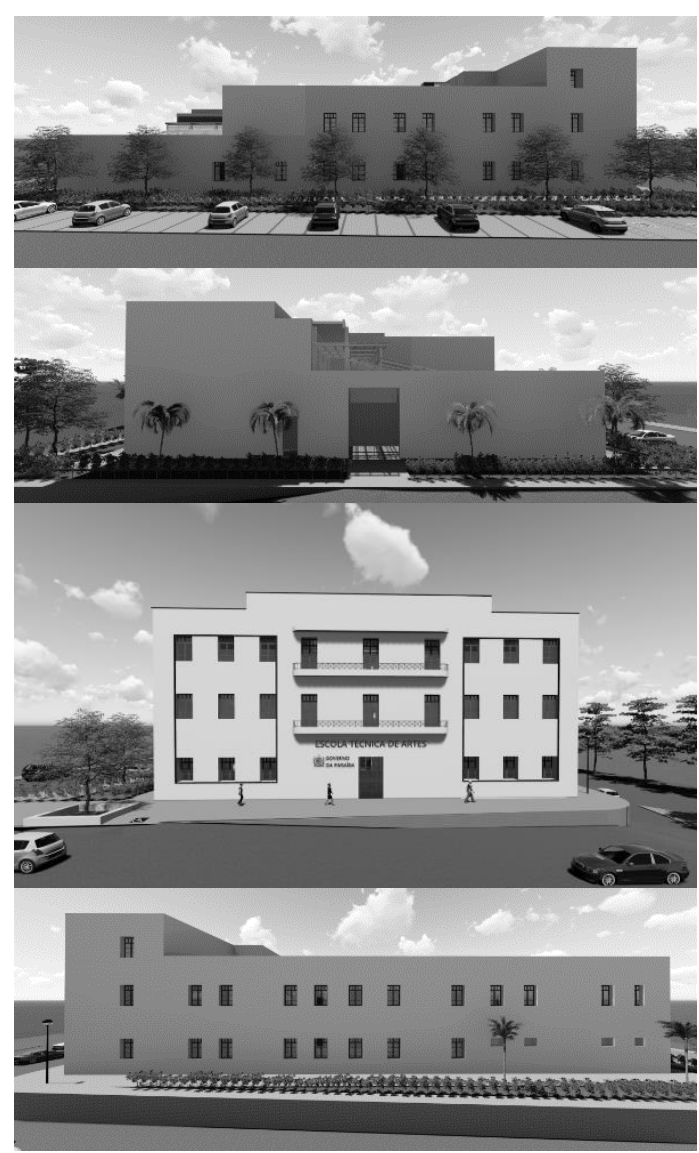

Figura 2- imagens da maquete eletrônica elaborada pela SUPLAN para a Escola Técnica de Artes e Danças da Paraíba

Fonte: SUPLAN- editado pelos autores 
Diante dos inúmeros danos que prédio sofreu, decorrentes da variedade de usos e adequações que não respeitaram o valor histórico do edifício, e intensificados pelo do abandono, resta evidenciado que algumas posturas projetuais, não seriam aceitas pelos teóricos do restauro mais radicais, como John Ruskin, visto que para este, após a perda do uso original o prédio deveria ser mantido, sem alterações ou intervenções e o que fosse perdido restaria assim. Porém o projeto de intervenção e readequação de uso possuiria mais respaldo sob a ótica de Camilo Boito, cujo preceito afirma que deve haver distinção entre o que é original e o que foi acrescentado ou modificado, evitando assim confundir o observador, ou produzir um falso histórico. Nesse sentido será adotado na presente intervenção a aplicação de materiais e técnicas, cujo efeito visual, evidencie a diferença temporal.

Também adequando o projeto ao conceito de Alouis Riegl, o qual afirma que se o uso determina o tipo da intervenção, desse modo resta respaldado o fato de ter sido autorizado pelos órgãos protetivos do patrimônio, a permissão para a adaptação de um presídio para uma escola, visto que o teórico supracitado afirmava que se o valor mais significativo do monumento dita a intervenção, assim sendo, se o uso for o mais importante, dada a necessidade de ocupação dos sítios históricos, este terá uma intervenção mais dinâmica, ao passo que se o valor mais elevado for a antiguidade, este deverá ser preservado como tal.

No caso em tela, a edificação precisa de novo uso, para que ocorra nova ocupação, possuindo assim, alento na teoria de Riegl. Já se avaliarmos a proposta pelo prisma de Brandi, veremos que o teórico mais recente, acaba por respaldar a protetividade e evita qualquer intervenção danosa, ou seja transforma a manutenção em finalidade imprescindível à perpetuação do patrimônio.

Pautado nas questões acima, a proposta projetual exigirá modificações de setores específicos do prédio, como a circulação vertical, que será remodelada, visto que as escadas apresentam um pé-direito baixo e irregularidade na dimensão dos degraus, especialmente na mudança de lance. Já no que diz respeito aos portadores de necessidades especiais a solução encontrada foi a implantação de elevadores no primeiro pátio do edifício. Esses contudo, não serão colocados de forma definitiva, sendo propostos em estrutura metálica, passível de serem removidas a qualquer tempo, sem o 
comprometimento da integridade do edifício reforçando a condição de reversibilidade apontada nas legislações de restauro.

Para as demais exigências previstas no programa de necessidades, foram estudadas adequações das salas para abrigar as tarefas de laboratórios de mídias áudio visuais, laboratórios de informática, biblioteca, auditório, entre outros. Todavia, alguns desafios tiveram que ser transpostos de forma mais evidente, pois as selas precisariam tornarem-se alojamentos e os bar
preciso uma compatibili das. Dessa forma foi

O levantamento da situação atual do edifício, efetuado pela SUPLAN em forma de relatório fotográfico, apontou potencialidades e fragilidades distribuídas na sua estrutura física na forma de patologias (Tabela 2).

\begin{tabular}{|c|c|}
\hline Local & Patologia \\
\hline Piso & $\begin{array}{l}\text { De modo geral, o piso apresenta desgaste em alguns ambientes e danos } \\
\text { permanentes em outros, como é o que das selas onde os presos eram mantidos. }\end{array}$ \\
\hline $\begin{array}{l}\text { Alvenaria/ } \\
\text { Estrutura }\end{array}$ & $\begin{array}{l}\text { Internamente a alvenaria apresenta boa aparência, contudo existem setores nos } \\
\text { quais foi constado descascamento do reboro, perda de revestimento e exposição da } \\
\text { armadura estrutural, cuja instalação de ferrugem já se encontra em processo } \\
\text { bastante avançado. Externamente a presença de infiltrações é bastante evidente, } \\
\text { além de patolo como fissuras e rachaduras. }\end{array}$ \\
\hline $\begin{array}{l}\text { Instalações } \\
\text { elétricas }\end{array}$ & $\begin{array}{l}\text { Em sua maioria apresentam rupturas e amarrações de fios expostos, bem como a } \\
\text { oxidação dos relógios de energia e conectores. }\end{array}$ \\
\hline $\begin{array}{l}\text { Instalações } \\
\text { sanitárias }\end{array}$ & $\begin{array}{l}\text { Existe uma problemática bem específica, posto que a diferença na espessura das } \\
\text { paredes, provoca uma má distribuição do sistema de esgoto e água do prédio, as } \\
\text { louças sanitárias encontram-se bastante deterioradas, especialmente aquelas } \\
\text { encontradas na ala prisional do prédio. Também foi percebido alterações } \\
\text { significativas nos banheiros de uso administrativo estes, visivelmente não pertenciam } \\
\text { ao prédio. }\end{array}$ \\
\hline Esquadrias & $\begin{array}{l}\text { Embora não tenha sido encontrada a presença de pragas biológicas, como cupins, } \\
\text { as esquadrias, especialmente as janelas, sofreram recortes para acomodarem as } \\
\text { caixas de ar condicionado, o que configura a deterioração não pelo tempo, mas pelo } \\
\text { uso inadequado de sistemas construtivos e acréscimos atuais no edifício. }\end{array}$ \\
\hline Coberta & $\begin{array}{l}\text { Existe a presença de infiltrações, algumas calhas estão desprendendo da sua } \\
\text { estrutura principal, as pérgolas da fachada frontal estão com a armadura exposta. }\end{array}$ \\
\hline Forro & O forro de gesso acrescido, desmoronou revelando as amarras e fiação exposta \\
\hline
\end{tabular}




\section{REFERÊNCIAS:}

AMAZONAS, Lei Orgânica do Município de Manaus - LOMAN ํㅡ 012 de 12 de setembro de 2001 - D.O.M.20.09.2001.

AMORIM, Luiz. Obituário Arquitetônico: Pernambuco Modernista. Recife: Gráfica Santa Marta, 2007

BRASIL, Constituição da República Federativa do Brasil. Brasília, DF: Senado Federal: Centro Gráfico, 1988.

COSTA, Marília Dissertação, 2015, p.23.

CURY, Izabelle (org.). Cartas Patrimoniais. 3ª ed. Rio de Janeiro: IPHAN, 2004

LERNER, Jaime. Acupuntura Urbana. 8ª ed. Rio de Janeiro: Record, 2015.

SOUZA.S.B. A. et al. Planejamento municipal e preservação do patrimônio cultural: conceitos básicos. Brasília, [s.n.], 1982.

SOUZA, Alberto e VIDAL, Wylnna. Sete plantas da capital paraibana, 1858-1940. João Pessoa: Editora Universitária da UFPB, 2010

STUCKERT FILHO, Gilberto Lyra. Parahyba: Capital em fotos. $3^{\underline{a}}$ Ed, 1 v .João Pessoa: Fotograf, 2007.

TIMOTHEO, Jussara B. M. et al. A memória urbana do centro histórico de João Pessoa: uma metodologia de inventário digital acadêmico com passado, presente e futuro. João Pessoa: Urbicentros. 2016

SIRVINKAS, Luís Paulo. Manual de Direito Ambiental. 3ª ed. São Paulo: Saraiva. 2005. p.279. 